\title{
Curative endoscopic resection of a huge pedunculated esophageal liposarcoma
}

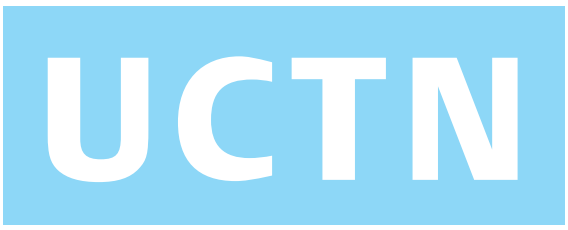

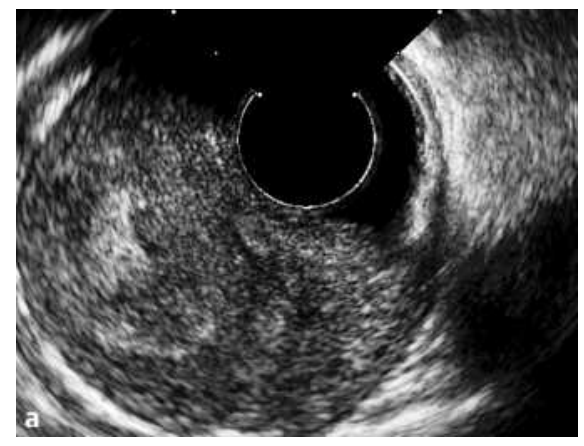
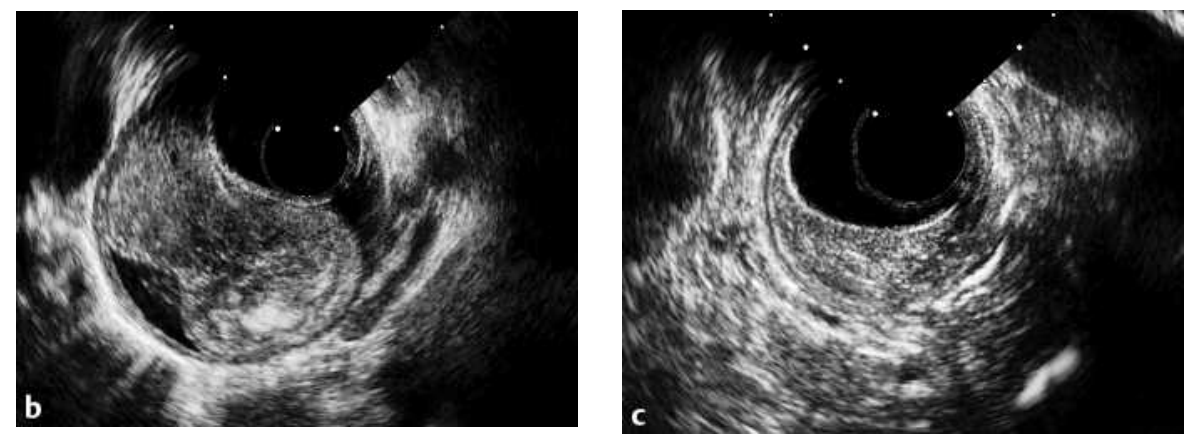

Figure 1 Endoscopic ultrasonography (EUS) of the esophageal liposarcoma. a The aboral segment, with regular layers in the esophageal wall; air is visible between the tumor and esophageal wall, indicating a tumor peduncle. $\mathbf{b}$ The middle third after the esophageal lumen has been filled with water, completely surrounding the tumor peduncle and showing a tumor waist. $\mathbf{c}$ The base near the pharyngoesophageal junction, with thickening of the wall and a hyperechoic structure with intact layers (no evidence of malignant tumor growth).
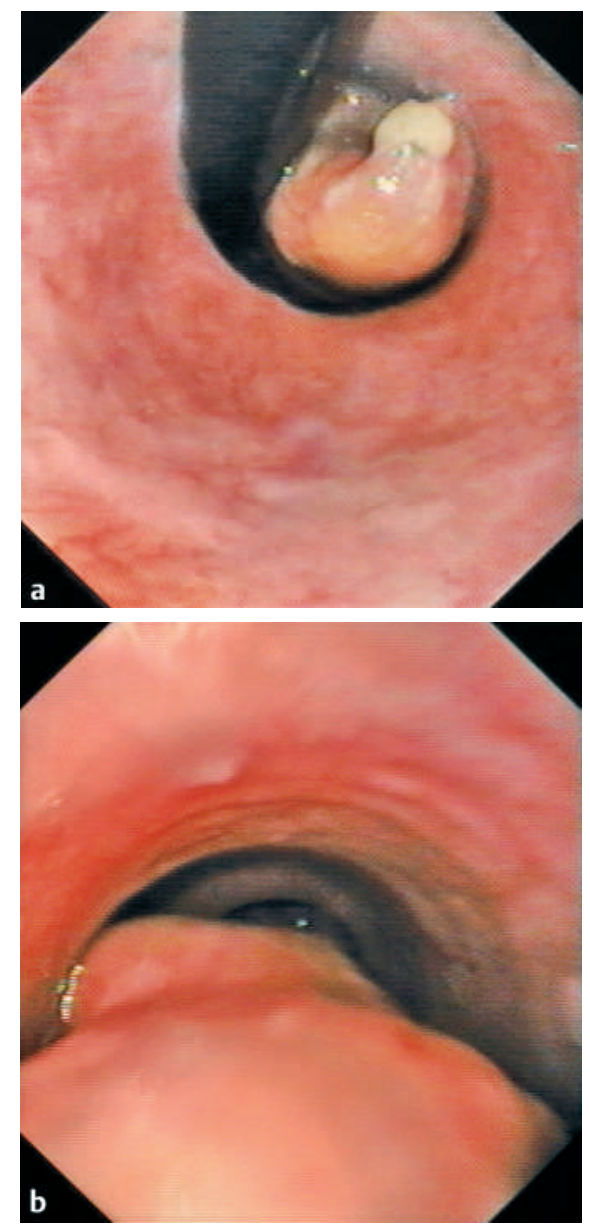

Figure 2 Endoscopic images of the esophageal liposarcoma. a The tip of the liposarcoma reaches the cardia, with slight mucosal erosions (subcardial inversion of the endoscope). b The middle third, showing a sausage-like intraluminal tumor mass along the esophageal wall (there are no signs of an epithelial lesion).
This is the first report of successful endoscopic resection of an esophageal liposarcoma, in which the patient's main symptom was dysphagia as a nonspecific sign $[1,2]$. The differential diagnosis of this type of lesion includes leiomyoma, lipoma, gastrointestinal stromal tumor (GIST), and sarcoma [2-6]. The first case of a liposarcoma within the esophagus was reported in 1983 [2,7].

In a 60-year-old man, endoscopic ultrasonography (EUS) revealed a pedunculated tumor $(4 \times 4 \times 20 \mathrm{~cm}$ in size) originating at the oral orifice of the esophagus and hanging down to the cardia along the wall of the esophagus (there were no enlarged locoregional lymph nodes) (Figure 1, 2). The patient declined surgery. A loop was placed from the tip to the base of the pedunculated tumor near the oral esophageal orifice, which made it possible to remove part of the tumor using diathermy. Bleeding at the tumor transection site was stopped with Hemoclips and epinephrine administration. The specimen was removed with an esophageal tube. The patient reported slight dysphagia and a foreign-body sensation in the pharynx. The residual tumor was therefore subsequently removed using an Inoue cap (a novel technique), into which the peduncle of the tumor was sucked and partially ablated with the loop at its anterior part, followed by dissection of the posterior part with the needle-knife (Figure 3). A check-up endoscopy showed no detectable residual tumor. Histological examination showed that the lesion was a dedifferentiated liposarcoma, with a dedifferentiating component of low malignancy with a good prognosis, including a highly differentiated adipocytic tumor component. The patient was discharged on the third day after the procedure. Check-up endoscopic examinations after 2,4 , and 12 months showed no recurrent tumor growth.

Esophageal liposarcomas are rare $[2,3,5$, $6,8]$; only 13 case reports are found in the literature, only some of which describe lesions of similarly gigantic size [1-4,7-9]. None of the previous reports have described curative resection of an esophageal liposarcoma as in this case $[2-4,6,9]$.

We favored EUS and repeated endoscopy for diagnosis of the lesion [1] instead of the computed tomography and magnetic resonance imaging procedures that are usually used $[9,10]$. Endoscopic resection was preferred to excision for this gigantic esophageal tumor for the following reasons:

- The patient expressed a strong desire to have a nonsurgical approach.

- There was EUS evidence of nonmalignant tumor characteristics.

- There was esophagoscopic evidence of a tumor peduncle.

- There was a potential for curative resection.

DOI: $10.1055 / s-2006-944902$ 


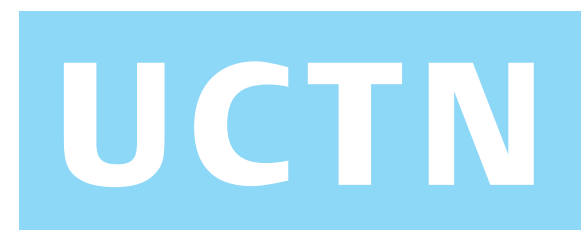

\section{References}

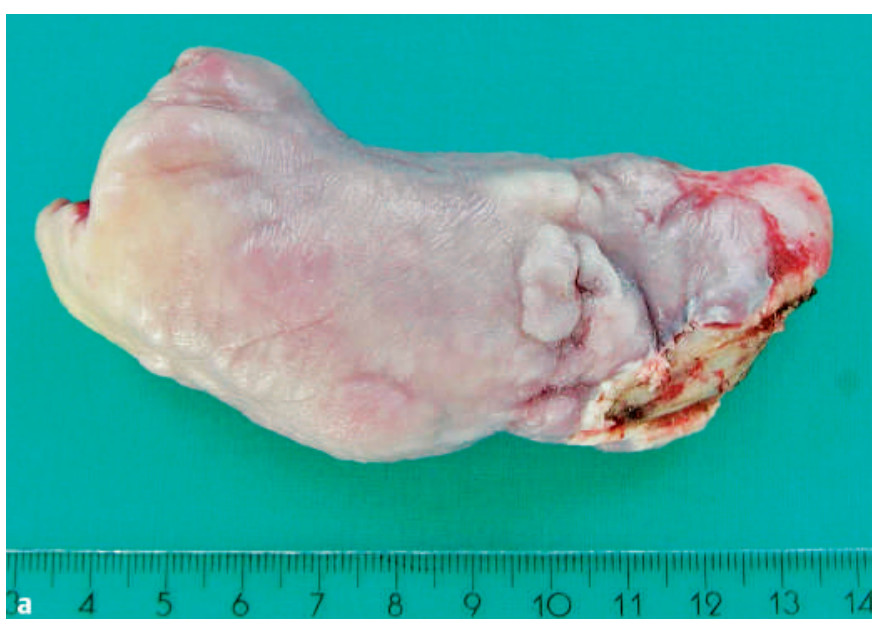

Figure 3 Specimens of the endoscopically excised esophageal liposarcoma. a The lower (aboral) two-thirds of the lesion, showing the flat resection area after the first resection step. $\mathbf{b}$ The oral third and smaller particles after the second resection procedure using Inoue's cap, loop, and the needle-knife.

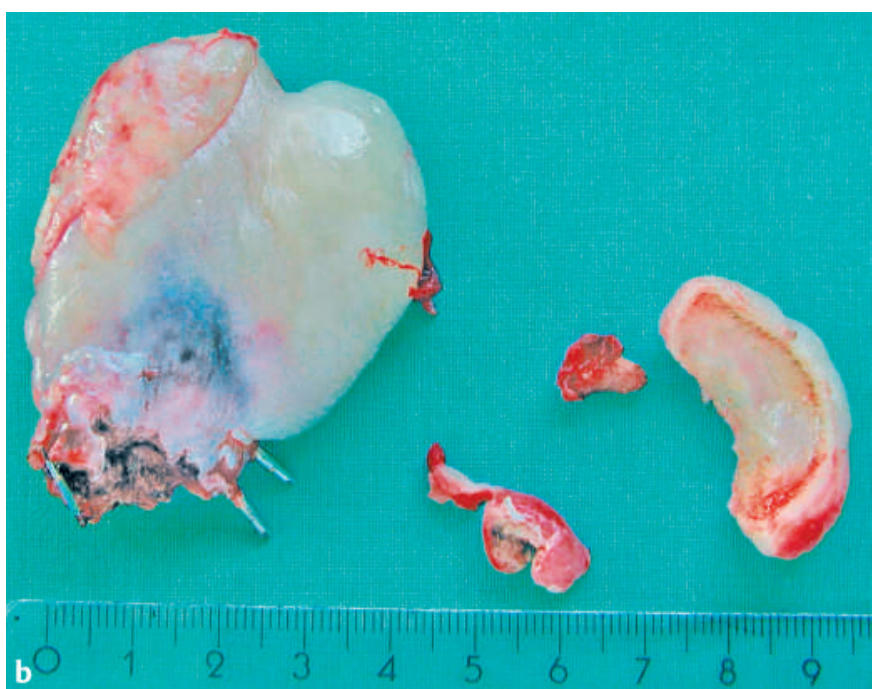

\section{Acknowledgment}

The authors are grateful to Prof. Katenkamp for providing an expert opinion on the histopathological diagnosis and specific findings in the specimen.

Endoscopy_UCTN_Code_CCL_1AB_2AC_3AB Endoscopy_UCTN_Code_TTT_1AO_2AG
${ }^{1}$ Bak YT, Kim JH, Kim JG et al. Liposarcoma arising in a giant lipomatous polyp of the esophagus. Korean J Intern Med 1989; 4: 86-89

2 Salis GB, Albertengo JC, Bruno M et al. Pedunculated liposarcoma of the esophagus. Dis Esophagus 1998; 11: 68-71

${ }^{3}$ Beaudoin A, Journet C, Watier A et al. Giant liposarcoma of the esophagus. Can J Gastroenterol 2002; 16: 377-379

${ }^{4}$ Boggi U, Viacava P, Naccarato AG et al. Giant pedunculated liposarcomas of the esophagus: literature review and case report. Hepatogastroenterology 1997; 44: $398-407$

${ }^{5}$ Cooper GJ, Boucher NR, Smith JH, Thorpe JA. Liposarcoma of the esophagus. Ann Thorac Surg 1991; 51: 1012 - 1013

${ }^{6}$ Garcia M, Buitrago E, Bejarano PA, Casillas J. Large esophageal liposarcoma: a case report and review of the literature. Arch Pathol Lab Med 2004; 128: 922 - 925

${ }^{7}$ Mansour KA, Fritz RC, Jacobs DM, Vellios F. Pedunculated liposarcoma of the esophagus: a first case report. J Thorac Cardiovasc Surg 1983; 86: 447-450

${ }^{8}$ Brehant O, Pessaux P, Hennekinne-Mucci S et al. Giant pedunculated liposarcoma of the esophagus. J Am Coll Surg 2004; 198: $320-321$

${ }^{9}$ Ruppert-Kohlmayr AJ, Raith J, Friedrich G et al. Giant liposarcoma of the esophagus: radiological findings. J Thorac Imaging 1999; 14: $316-319$

${ }^{10}$ Chung JJ, Kim MJ, Kim JH et al. Imaging findings of giant liposarcoma of the esophagus. Yonsei Med J 2003; 44: 715 -718

\section{Corresponding author}

\section{U. Will, M.D.}

Dept. of Gastroenterology

Municipal Hospital

Strasse des Friedens 122

07548 Gera

Germany

Fax: $\quad+49-365-8282402$

Email: uwe.will@wkg.srh.de 